\title{
RETINAL VASCULAR MICROMETRY BY THE USE OF A MEASURING OPHTHALMOSCOPE*
}

\author{
BY \\ MARJORY B. SNODGRASS \\ The Eye Infirmary, Glasgow
}

THE eye is the only part of the body in which blood vessels can readily be observed. In disease, retinal blood vessels may show pathological variations in calibre, the severity of which at times reflects the progress of the disease, whether local as in retinitis pigmentosa, or systemic as in spastic hypertension. Spasticity of retinal vessels may show measurable alteration after treatment, in particular during the exhibition of vasodilator drugs. It was felt that a portable instrument sufficiently accurate to measure variations in the calibre of retinal vessels would be of clinical value.

Attempts have previously been made to obtain absolute measurements of delineable, ophthalmoscopically visible retinal structures in the fundus. Numerous methods have been described since Zander (1864) first used a graticule with indirect ophthalmoscopy to measure the calibre of retinal arterioles. Lo Cascio (1922) used a graticule on the heliometer principle, and Lobeck (1934), working independently, produced a more effective heliometer method using the Gullstrand ophthalmoscope. The graticule described by Morgan (1927), which was used by many research workers, was modified by Neame (1936). A further modification, using a prism displacement method, was introduced by Cusick, Benson, and Boothby (1940). Angioscotometry (Solanes, 1947) and modern fundus photography (Lambert, 1934) are two other methods of vascular micrometry.

Some of these methods involve the use of complicated apparatus and others are insufficiently accurate to measure the calibre of the smaller retinal blood vessels. For routine hospital work, it was felt that some adaptation of Morgan's graticule used in conjunction with Keeler's electric measuring ophthalmoscope would prove a practical method.

\section{Apparatus}

A graticule was designed with gauges of ten widths ranging from $0.01 \mathrm{~mm}$. to $0.1 \mathrm{~mm}$. (Fig. 1, overleaf). These are inserted into the central clear area of a Morgan-type graticule. Each gauge consists of a central black cross bordered by a clear area on each side; the cross and the flanking blank area are of the prescribed width. This graticule was made for me by Messrs. Keeler and fits their 


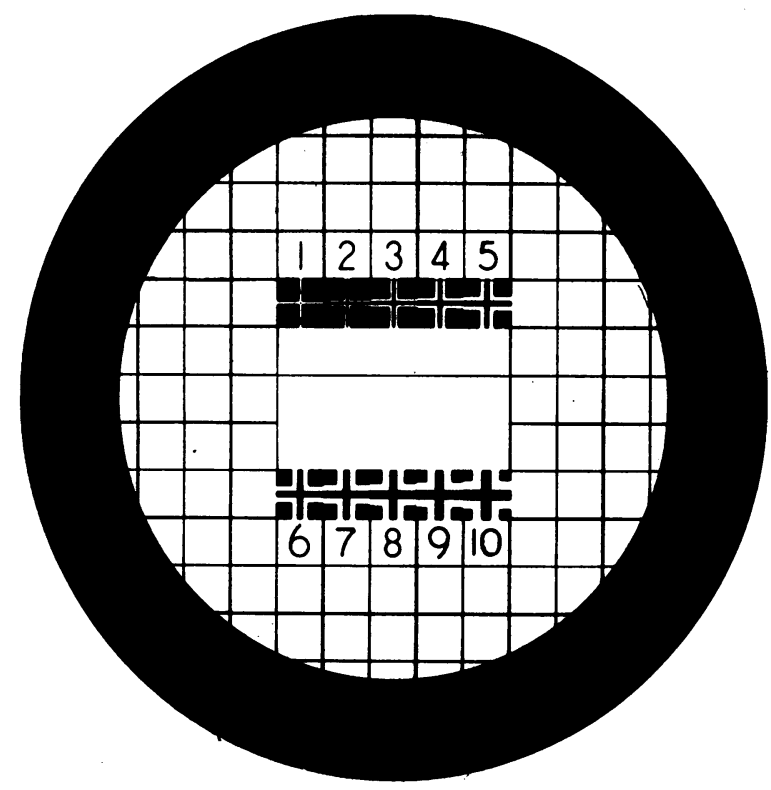

FIG. 1.-Diagram of graticule.

measuring ophthalmoscope. The graticule can be rotated and moved up and down on the ophthalmoscope and, by moving a special focusing button, its image may be focused through the objective on to the fundus (Fig. 2, opposite). The separation between the objective and the graticule is recorded on an illuminated scale in the ophthalmoscope which measures this separation in dioptres when the objective is at the anterior focal point of the eye.

Standardization.-Use was made of the fact that, because of the optical system of the ophthalmoscope, any alteration in the estimated size of a retinal structure due to ametropia, compared with its real size, should remain constant if the graticule is kept in the same dioptric position in the ophthalmoscope. The measurements obtained will only be absolute if the objective of the instrument is at the anterior focal point of the eye. This position is difficult to maintain accurately and, in the following investigation, the ophthalmoscope is held as close to the eye as is comfortably possible in the first examination. Subsequent observations are carried out with the graticule pre-set at the dioptric position recorded at the first examination. Thereafter its image is brought into sharp focus on the fundus by moving the ophthalmoscope nearer to, or further from, the patient's eye, so bringing the instrument to the same distance from the patient's eye as in the first examination. Thus consecutive observations are directly comparable.

\section{Observations}

In order to test the accuracy of the instrument, a series of fifteen observations was carried out on young adults showing no clinical evidence of disease of the cardiovascular system. The examinations were carried out in a darkened room. The pupils were dilated by the instillation of one drop of 


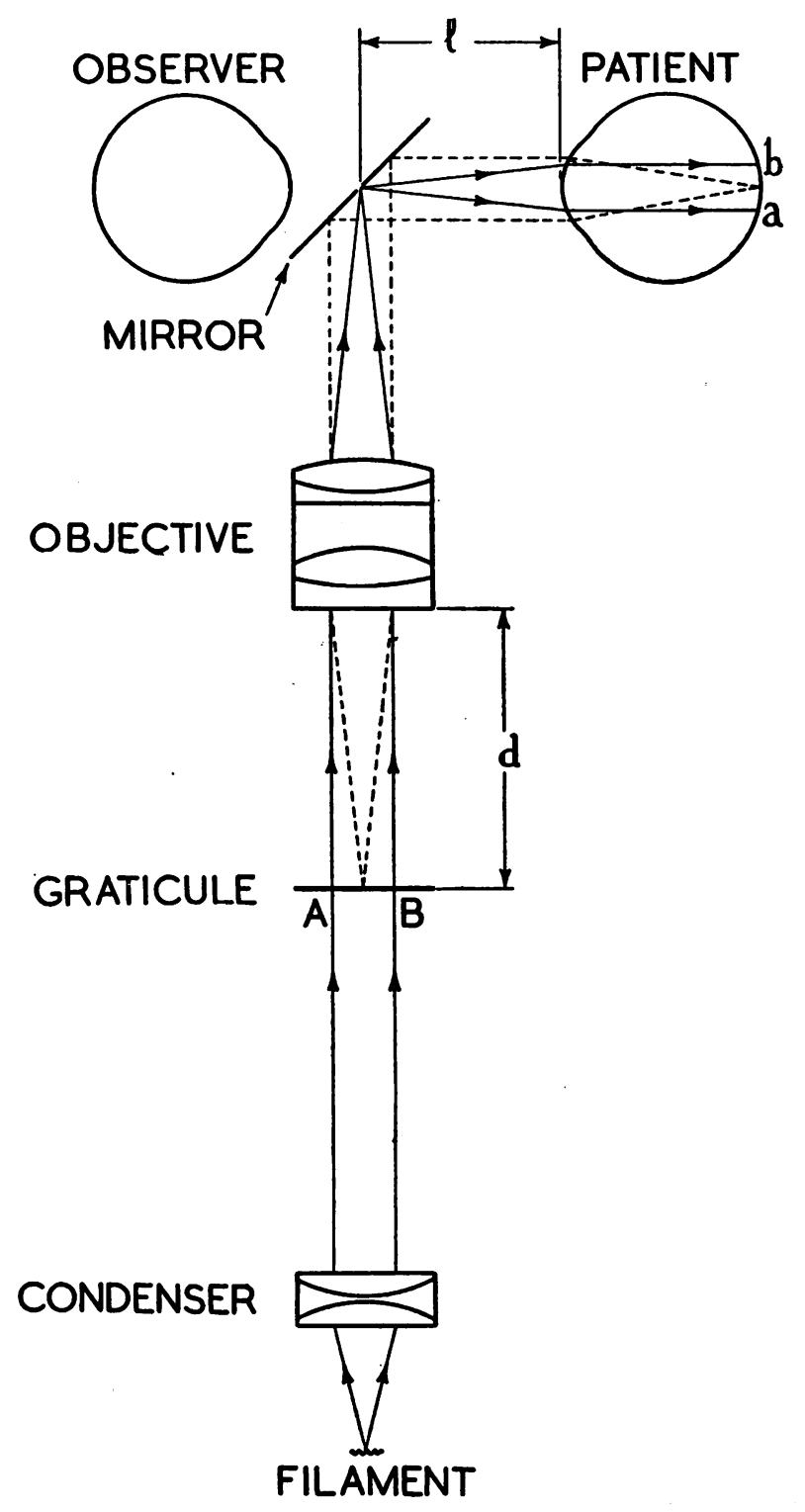

Fig. 2.-Diagram of optical system.

homatropine 2 per cent. and cocaine 1 per cent. and the patient was requested to keep steady fixation on a point of light at $5 \mathrm{~m}$. distance. At the first examination, the ophthalmoscope was held as close as possible to the patient's eye (i.e. at about the anterior focal point), and was focused on selected arterioles. The graticule was then brought into accurate focus on the same area. A diagram, including the sections of the retinal vessels measured, was 
made of sufficient accuracy to permit their recognition on subsequent occasions, and the dioptric position of the graticule was recorded on this. The estimated width of the calibre of the selected sections of the arterioles was recorded separately. One or two further examinations were carried out on subsequent days, no reference being made to the previous measurements. From the previously recorded diagram, the dioptric position of the graticule was "set" and further readings of the calibre of the same sections of the arterioles were made by adjusting the distance of the ophthalmoscope from the subject's eye until the graticule was brought into focus on the fundus. Thus two, and in most cases three, independent readings of the calibre of the selected sections of the retinal arterioles were obtained.

A series of a hundred such sets of observations was made. The variation of each reading from the arithmetic mean of its set of readings was calculated and the results are shown in Fig. 3.

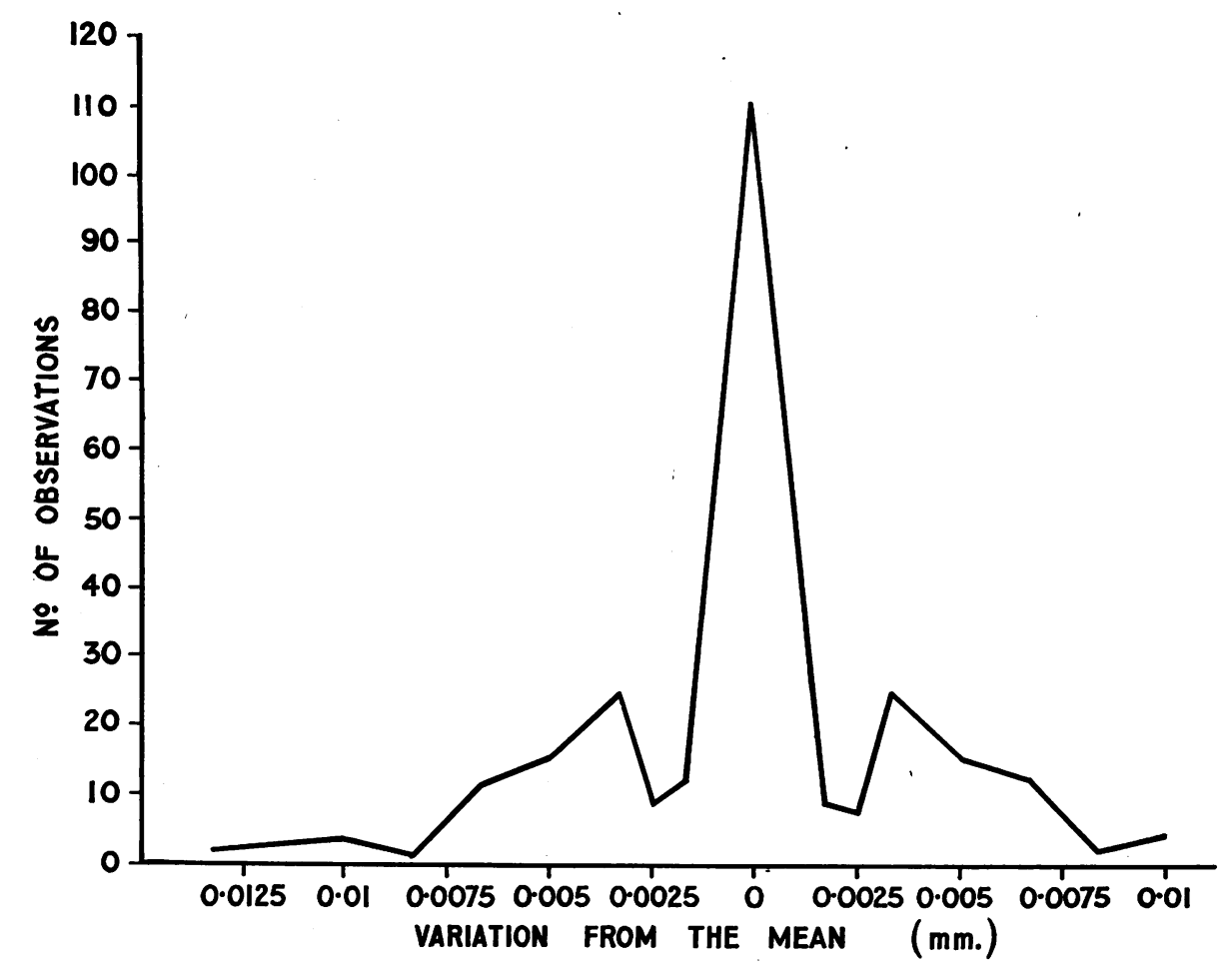

Fig. 3.-Variation of each observation from the mean of its set of observations.

The maximum variation within each set of observations is shown in the Table opposite.

\section{Conclusion}

95 per cent. of the readings had a maximum variation of less than the 


\section{TABLE}

\section{MAXIMUM VARIATION FOR EACH SET OF OBSERVATIONS WITHIN THE} SET FROM THE ARITHMETIC MEAN OF THE SET

\begin{tabular}{c|c}
\hline $\begin{array}{c}\text { Maximum Variation as } \\
\text { Fractions of Variation } \\
\text { in Gauge Widths } \\
(0 \cdot 01 \mathrm{~mm} .)\end{array}$ & Number of Sets \\
\hline 0 & 42 \\
\hline$\frac{1}{4}$ & 7 \\
\hline$\frac{1}{3}$ & 9 \\
\hline$\frac{1}{2}$ & 15 \\
\hline$\frac{2}{3}$ & 19 \\
\hline$\frac{5}{6}$ & 3 \\
\hline 1 & 4 \\
\hline $1 \frac{1}{3}$ & 1 \\
\hline
\end{tabular}

difference between two neighbouring gauge widths $(0.01 \mathrm{~mm}$.). If a variation of at least one gauge width is noted, this can be considered significant.

This method of retinal vascular micrometry has a fair degree of accuracy and, although it is time-consuming and involves cooperation from the subject, it should be applicable in clinical work for consecutive observations of the measurement of some retinal structure, and may also be used in research demanding controlled and accurate observations.

This work was assisted by the Spencer Research Trust.

I wish to thank Dr. J. H. Wright, Glasgow Royal Infirmary, for allowing me to examine patients under his care for the purpose of this investigation and Keeler Optical Products Ltd. for their help in making the special graticule and for the use of their blocks in the reproduction of Figs 1 and 2.

\section{REFERENCES}

Cusick, P. L., Benson, O. O., jr., and Boothby, W. M. (1940). Proc. Mayo Clin., 15, 500.

LAMBERT, R. K. (1934). Arch. Ophthal. (Chicago), $12,868$.

LOBECK, E. (1934). v. Graefes Arch. Ophthal., 133, 152.

Lo Cascio, G. (1922). Riv. ott. e meccan di precis., 2, S1 (Abs. (1923). Zbl. ges. Ophthal., 9, 189).

MORGAN, O. G. (1927). Brit. J. Ophthal., 11, 339.

NeAME, H. (1936). Trans. ophthal. Soc. U.K., 56, 155.

SOlanes, M. P. (1947). Amer. Heart J., 33, 733.

ZANDER, A. (1864). "The Ophthalmoscope: Its Varieties and its Use", trans. R. B. Carter, p. 101. Hardwicke, London. 